\title{
Diversity of bacteria and archaea in the rhizosphere of bioenergy crop Jatropha curcas
}

\author{
Garima Dubey $^{1} \cdot$ Bharati Kollah $^{1}$ - Vijay Kumar Gour ${ }^{2}$ Arvind Kumar Shukla ${ }^{1}$ \\ Santosh Ranjan Mohanty ${ }^{1}$
}

Received: 9 July 2016/Accepted: 11 October 2016/Published online: 2 December 2016

(C) The Author(s) 2016. This article is published with open access at Springerlink.com

\begin{abstract}
Plant-microbial interaction in rhizosphere plays vital role in shaping plant's growth and ecosystem function. Most of the rhizospheric microbial diversity studies are restricted to bacteria. In natural ecosystem, archaea also constitutes a major component of the microbial population. However, their diversity is less known compared to bacteria. Experiments were carried out to examine diversity of bacteria and archaea in the rhizosphere of bioenergy crop Jatropha curcas (J. curcas). Samples were collected from three locations varying widely in the soil physico-chemical properties. Diversity was estimated by terminal restriction fragment length polymorphism (TRFLP) targeting $16 \mathrm{~S}$ rRNA gene of bacteria and archaea. Fifteen bacterial and 17 archaeal terminal restriction fragments (TRFs) were retrieved from J. curcas rhizosphere. Bacterial indicative TRFs were Actinobacteria, Firmicutes, Acidobacteria, Verrumicrobiaceae, and Chlroflexi. Major archaeal TRFs were crenarchaeota, and euryarchaeota. In case of bacteria, relative fluorescence was low for TRF160 and high for TRF51, TRF 420. Similarly, for archaea relative fluorescence of TRF 218, and TRF 282 was low and high for TRF 278, TRF468 and TRF93. Principal component analysis (PCA) of bacterial TRFs designated PC 1 with $46.83 \%$ of variation and $\mathrm{PC} 2$ with $31.07 \%$ variation. Archaeal TRFs designated $90.94 \%$ of variation by PC1 and $9.05 \%$ by PC2. Simpson index varied from 0.530 to 0.880 and Shannon index from 1.462 to 3.139 for bacteria. For archaea,
\end{abstract}

Santosh Ranjan Mohanty mohantywisc@gmail.com

1 Indian Institute of Soil Science, Nabibagh, Bhopal 462038, India

2 Department of Plant Breeding and Genetics, J.N. Agricultural University, Krishinagar, Jabalpur 482004, India
Simpson index varied from 0.855 to 0.897 and Shannon index varied from 3.027 to 3.155 . Study concluded that rhizosphere of $J$. curcas constituted of diverse set of both bacteria and archaea, which might have promising plant growth promoting activities.

Keywords Diversity - Bacteria - Archaea - Rhizosphere · Bioenergy crop · Jatropha curcas

\section{Introduction}

Bioenergy crop Jatropha curcas (J. curcas) is a member of Euphorbeaceae family. Recently, it is promoted worldwide for bioenergy production, soil health improvement, climate change mitigation, carbon sequestration and socio economic improvement (Islam et al. 2014). J. curcas survives under limited nutrient and harsh environmental condition. $J$. curcas adapt to grow under salt stress, high temperature. Because of these growth abilities, J. curcas has been used for soil reclamation. Its rhizosphere harbors myriad of microbial community those regulate nutrient uptake and adaptation to extreme environment. Many heterotrophs, $\mathrm{N}_{2}$ fixers, and $\mathrm{P}$ solubilizers inhabit in its rhizosphere (Mohanty et al. 2012). Rhizosphere of Jatropha possesses diverse group of arbuscular mycorrhizal fungi (AMF), actinomycetes, and many plant growth-promoting rhizobacteria (PGPR) (Pérez and Schenck 1990). Plant growth-promoting gamma-proteobacterium, Enterobacter cancerogenus has also been isolated from the rhizosphere of $J$. curcas. These microbial species produce growth hormone ACC (1-amino-cyclopropane-1-carboxylate) deaminase, phytases, auxin, IAA (indole acetic acid), siderophores, ammonia and solubilize phosphate. Like $J$. curcas, most of the plants have numerous PGPRs in their 
rhizosphere, but they often fail to grow under challenging environment. However, it is unclear how $J$. curcas adapts to extreme (water and nutrient limitation) conditions. We hypothesize that $J$. curcas harbors certain microbial groups in its rhizosphere which might have different plant-microbial interaction than commonly known. Possibly archaea predominate in $J$. curcas rhizosphere, because archaea are known to occur in challenging environments. The present study was undertaken to reveal the diversity of bacteria and archaea in the rhizosphere of J. curcas.

\section{Materials and methods}

\section{Site characterization}

Sampling was carried out during July 2014 from three sites located at the Jabalpur, Noida, and Bhopal (Table 1). Jatropha curcas is being grown in these locations since 2006. Samples from Bhopal was located near the village Gunga, Bhopal, Madhya Pradesh, India $\left(23^{\circ} 45^{\prime} \mathrm{N}\right.$ latitude, $77^{\circ} 36^{\prime} \mathrm{E}$ longitude and $485 \mathrm{~m}$ above mean sea level). Geographically, this location has semi-arid and sub-tropical climate. It has dry summer and cold winter with a mean annual air temperature of $25^{\circ} \mathrm{C}$, rainfall $1208 \mathrm{~mm}$ and humidity $56 \%$. It experiences southwestern monsoon rains in JulySeptember. The experimental soil belongs to vertisols that is, Hypothermic family of Typic Haplusterts popularly known as "black cotton soil". Samples from Jabalpur were collected from experimental farm of Jawaharlal Nehru Krishi Vishwya Vidyalaya, Jabalpur $\left(24^{\circ} 30^{\prime} \mathrm{N}\right.$ latitude, $80^{\circ} 15^{\prime} \mathrm{E}$ longitude and $306.06 \mathrm{~m}$ above from sea level). The soil of experimental field was sandy clay loam. Soil samples were also collected from Noida, Uttar Pradesh $\left(25^{\circ} 53^{\prime} \mathrm{N}\right.$ latitude, $77^{\circ} 39^{\prime} \mathrm{E}$ longitude and about $656 \mathrm{~m}$ above from sea level). The soil characteristics of the experimental site before start of the study were analyzed and presented in Table 1. The soils were obtained by removing the top soil $(\sim 1-2 \mathrm{~cm})$ and collecting the next $10 \mathrm{~cm}$ with a shovel near plant's root (Mohanty et al. 2015). Three randomly collected individual samples were mixed to make a composite sample. Soils were stored in plastic bags at $4{ }^{\circ} \mathrm{C}$ to prevent moisture loss and were used within $48 \mathrm{~h}$ of collection.

\section{DNA extraction from soil and PCR amplification}

Freshly collected rhizospheric soils of $0.5 \mathrm{~g}$ were used to extract DNA using ultraclean DNA extraction kit (MoBio, USA) as described by manufacturer. The extracted DNA was dissolved in $50 \mu \mathrm{l}$ TE buffer $(10 \mathrm{mM}, \mathrm{pH} 8.0)$ and stored at $-20{ }^{\circ} \mathrm{C}$ until further analysis. The PCR was performed in a total volume of $50 \mu$ containing $20 \mathrm{ng}$ of DNA template, $1 \mathrm{U}$ of Taq DNA polymerase (NEB, USA), $0.4 \mu \mathrm{M}$ of each primer, and $1 \times$ PCR buffer (PCR Buffer II, Applied biosystems, CA, USA). The bacterial primers were $8 f$ ( $5^{\prime}$-AGAG TTT GAT CCT GGC TCA G-3') and 518r (5'-CTC CTA CGG GAG GCA GCA G-3'). The Achaeal primers were $109 \mathrm{~F}\left(5^{\prime}\right.$-ACK GCT CAG TAA CAC GT-3') and 915R (5'-GTG CTC CCC CGC CAA TTC $\left.C T-3^{\prime}\right)$. Forward primers were labeled with 6-Carboxyfluorescein (FAM) at the $5^{\prime}$ end. Thermal cycling for bacterial $16 \mathrm{~s}$ rRNA was carried out in a PCR instrument (Step one plus, $\mathrm{ABI}$ ) by an initial denaturizing step at $94{ }^{\circ} \mathrm{C}$ for $4 \mathrm{~m}, 35$ cycles of $94{ }^{\circ} \mathrm{C}$ for $1 \mathrm{~m}, 50{ }^{\circ} \mathrm{C}$ (bacteria) or $56{ }^{\circ} \mathrm{C}$ (archaea) for $30 \mathrm{~s}, 72{ }^{\circ} \mathrm{C}$ for $45 \mathrm{~s}$; final extension carried out at $72{ }^{\circ} \mathrm{C}$ for $5 \mathrm{~m}$. The presence and sizes of the PCR amplification products were determined by agarose (1\%) gel electrophoresis. PCR products were purified from the reaction mix using the PCR purification kit (Axygen, USA).

\section{Terminal restriction fragment length polymorphism (T-RFLP) analysis and phylogenetic affiliation}

Efficiency of the T-RFLP depends on the coverage of the restriction enzymes. Efficiency of three restriction enzymes (Msp, Rsa and Alu) evaluated to identify best restriction enzyme for diversity analysis. Bacterial and archaeal 16SrRNA gene sequences were downloaded from GenBank. Web based tools (MiCA: T-RFLP Analysis APLAUS+) were used for in silico analysis (Shyu et al. 2007). Virtual amplification and digestion was carried out with respective primers and different restriction enzymes as per instructions. Based on the number of terminal restriction fragments (TRFs) and coverage restriction enzymes were finalized. In silico analysis identified RsaI $\left(\mathrm{GT}^{\wedge} \mathrm{AC}\right)$ as best restriction enzyme for bacteria and Alu $\left(\mathrm{AG}^{\wedge} \mathrm{CT}\right)$ for archaea. Amplicons were digested by

Table 1 Physico chemical properties of soils collected from different sampling sites

\begin{tabular}{|c|c|c|c|c|c|c|c|c|c|}
\hline Location & Textural class & $\begin{array}{l}\mathrm{pH} \\
(1: 2.5 \text { soil } \\
\text { to water })\end{array}$ & $\begin{array}{l}\text { EC }(1: 2.5 \text { soil to } \\
\left.\text { water, } \mathrm{dSm}^{-1}\right)\end{array}$ & $\begin{array}{l}\text { CEC } \\
\left(\mathrm{cmol}^{(\mathrm{p}+)}\right. \\
\left.\mathrm{kg}^{-1}\right)\end{array}$ & $\begin{array}{l}\text { Organic C } \\
\left(\mathrm{g} \mathrm{kg}^{-1}\right)\end{array}$ & $\begin{array}{l}\text { Total } \\
N\left(\mathrm{~g} \mathrm{~kg}^{-1}\right)\end{array}$ & $\begin{array}{l}\text { Sand } \\
(\%)\end{array}$ & $\begin{array}{l}\text { Silt } \\
(\%)\end{array}$ & $\begin{array}{l}\text { Clay } \\
(\%)\end{array}$ \\
\hline Bhopal & Heavy Clayey & 7.5 & 0.43 & 44.5 & 5.7 & 0.61 & 15.2 & 30.3 & 54.5 \\
\hline Jabalpur & Clayey Typic Haplustert & 7.2 & 0.22 & 9.8 & 4.5 & 0.22 & 25.3 & 17.9 & 56.8 \\
\hline Noida & Sandy clay loam & 8.1 & 0.24 & 10.6 & 6.8 & 0.57 & 47.4 & 27.2 & 24.8 \\
\hline
\end{tabular}


respective restriction enzymes at $37{ }^{\circ} \mathrm{C}$ for $3 \mathrm{~h}$ and inactivated at $65{ }^{\circ} \mathrm{C}$ for $20 \mathrm{~min}$ as per manufacturer's instruction (New England Biolabs, USA). The digested products were sent for fragment analysis to Macrogen Inc, Korea (www.macrogen.com). Briefly, aliquots of $10 \mu \mathrm{l}$ were mixed with $15 \mu \mathrm{l} \mathrm{HiDi}$ formamide (Applied Biosystems) and $0.3 \mu \mathrm{l}$ of the internal DNA fragment length standard (500 LIZ, Applied Biosystems). Fragment analysis was conducted on a 3730xl DNA analyzer (Applied Biosystems). T-RFs were determined using the GeneScan software package (version 1.0, Applied Biosystems), Fragments between 50 and 500 bp were included in the analysis. Peak area data were normalized for uniform distribution. Each peak expressed as a percentage of the total peak area in the profile. Peaks comprising $<1 \%$ of the total area were removed from the analysis (Mohanty et al. 2007). Phylogenetic assignments were attempted from T-RFLP patterns using the web-based program PAT (MiCA) (Shyu et al. 2007). Although identifications are tentative, however, this in silico approach has been successfully validated with clone libraries in other studies (Mohanty et al. 2007; Yi et al. 2009; Tipayno et al. 2012). It allowed retrieval not only of the composition of bacteria down to the genus level, but also of many ribotypes related to a specific organism from environmental samples (Rösch and Bothe 2005).

\section{AMMI model, PCA, diversity and cluster analysis}

Raw T-RFLP profiles data from Peak Scanner were pretreated using the online software T-REX to find out the most prominent TRFs (Culman et al. 2008). Microbial diversity was calculated from the relative fluorescence intensity of TRFs. The environmental variable was sampling location. Three replicate samples were computed with threshold limit $3 \mathrm{bp}$ (fragments of $3 \mathrm{bp}$ difference will be grouped as one representative) using the web-based tool (T-Rex). Output files were two way analysis of variance (ANOVA), additive main effects and multiplicative interaction (AMMI) model, and the abundance graph. The AMMI model is used to differentiate the effect of environmental factors on the TRFLP pattern (Culman et al. 2008). Multivariate T-RFLP data analysis carried out after organizing the data into a species (T$\mathrm{RFs}) \times$ samples matrix. This matrix contain three distinct sources of variation: (1) main effects for T-RFs, also called operational taxonomic units (OTUs); (2) main effects for Environments (E), also called treatments (source of sampling) and (3) interaction effects for $\mathrm{T}-\mathrm{RF} \times$ Environment $(\mathrm{T} \times \mathrm{E})$. The method generally analyzed all three sources of variation simultaneously. To identify the major variables (TRFs) and the complexity of interaction with the environments, Principal Component Analysis (PCA) was carried out after ln transformation and normalization of data. PCA often reveals previously unsuspected correlations among the variables, thereby allowing interpretations that would not otherwise be apparent (Johnson and Wichern 2002). PCA analysis was interpreted graphically by constructing biplots, with the original variables drawn as vectors that summarize the correlation among the variables. PCA biplots are a convenient way of mapping the original variables, because the angles between the variables express their level of the correlation. Biplot was made using the values of three replicated observations. Average TRF data were subjected to cluster analysis using the Euclidean distance measure. Dendrogram was constructed using an un-weighted pair-group method with arithmetic mean. Diversity statistics were calculated from normalized profiles of individual samples using the number and area of peaks in each profile as representations of the number and relative abundance of phylotypes (Dunbar et al. 2001). Phylotype richness (S) was calculated as the total number of distinct TRF sizes in a profile. The Shannon diversity index, Simpson index and Evenness estimated using statistical package PAST (ver 2.12). All other analysis were carried out using agricolae and vegan package of the statistical software $R$ ver 2.15.1 (Oksanen et al. 2007; De Mendiburu 2014).

\section{Results}

\section{TRFLP analysis of bacteria and archaea}

There were altogether 15 bacterial TRFs retrieved from the rhizospheric samples of J. curcas (Fig. 1). Fluorescence intensity of bacteria varied from 11 to $89 \%$. Among those TRF75, TRF160, TRF214, and TRF499 had lowest intensity, while, TRF51 had highest intensity. Similarly, 17 archaeal TRFs were obtained from J. curcas rhizosphere. Fluorescence intensity of these TRFs varied from 11.11 to 67\%. TRF57, TRF164 and TRF468 had lowest and TRF186, TRF278, and TRF 497 exhibited highest fluorescence intensity.

\section{Relative abundance of bacteria and archaeal TRFs}

The relative abundance of the bacteria and archaea was evaluated as fluorescence of individual peaks in relation to the total fluorescence (Fig. 2). Relative fluorescence of the bacterial TRFs varied from $0.94 \%$ (TRF274, TRF367) to $21.38 \%$ (TRF468) in samples of Bhopal. In case of Jabalpur, relative fluorescence intensity ranged from $1.46 \%$ 
Fig. 1 Terminal restriction fragment of bacteria and archaea prevalence in the rhizosphere of the Jatropha curcas. $X$ axis represents base pairs, $Y$ axis represents TRFs abundance in the rhizospheric samples
Fig. 2 Relative fluorescence of bacterial (left) and archaeal (right) ribotypes (TRFs) in rhizosphere of Jatropha curcas collected from different locations. $X$ axis represents sampling locations (Bhopal, Jabalpur and Noida). $Y$ axis represent relative fluorescence of the TRFs. Each data points are average of three replicated observations
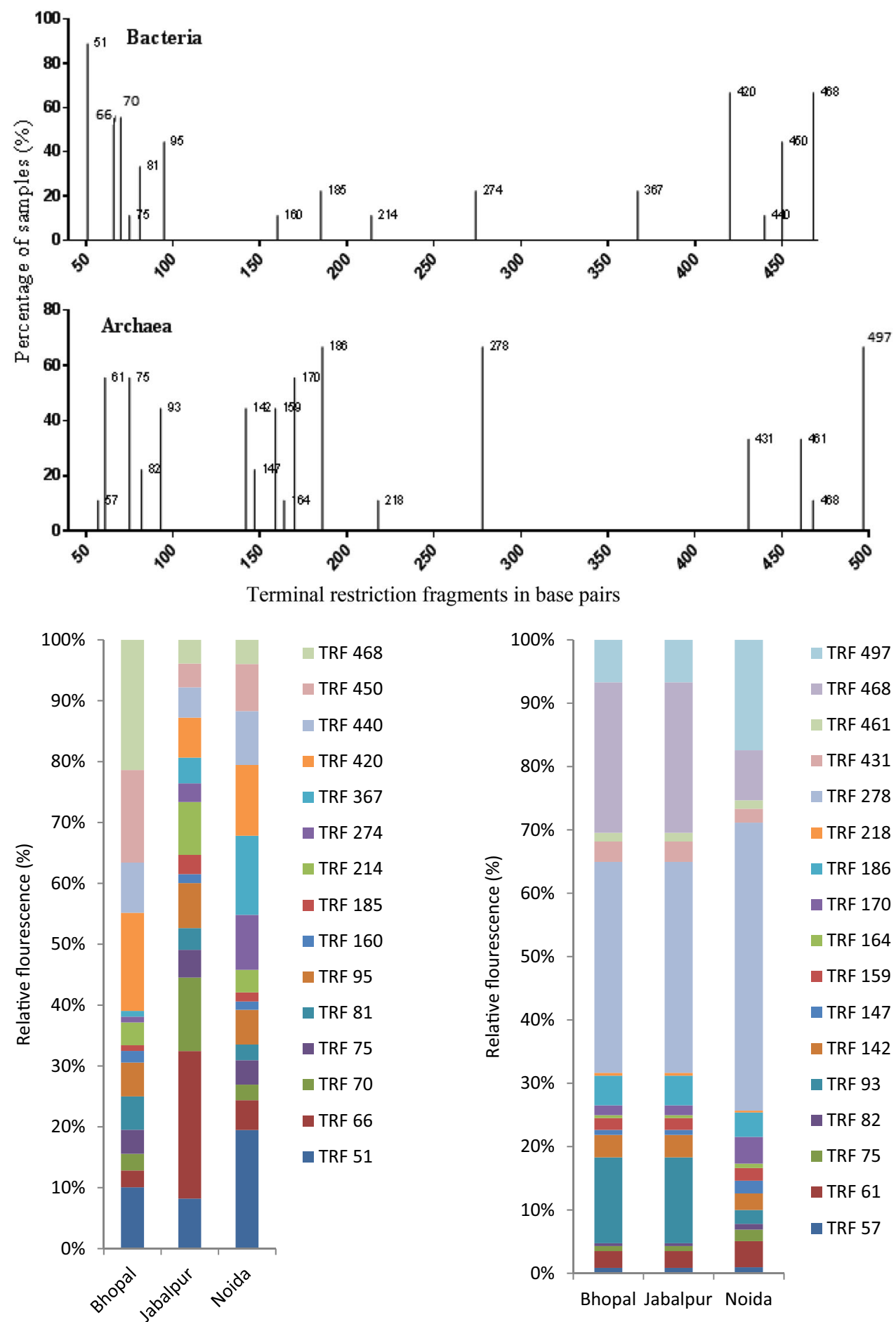

$33.32 \%$ (TRF278). In case of Noida, the relative fluorescence varied from $0.30 \%$ (TRF 218) to $17.42 \%$ (TRF497).

\section{Taxonomic assignment}

archaea also followed similar pattern in the samples. Relative fluorescence of archaeal TRFs ranged from $0.44 \%$ (TRF82) to $23.75 \%$ (TRF468) in Bhopal. Jabalpur samples exhibited relative fluorescence from $0.43 \%$ (TRF218) to
The affiliation of TRFs representing different taxonomic units of bacteria and archaea is presented in Table 2. Major 
Table 2 Tentative major bacterial and archaeal TRFs and their taxonomic affiliation

\begin{tabular}{lllll}
\hline Bacteria & & & \multicolumn{2}{l}{ Archaea } \\
\cline { 1 - 2 } \cline { 5 - 5 } TRFs & Affiliation & & TRFs & Affiliation \\
\hline 51 & Bifidobacteriaceae & & 57 & Uncultured archaea \\
66 & Lactobacillaceae & & 61 & Uncultured archaea \\
70 & Moraxellaceae & & 75 & Methanomicrobiaceae \\
75 & Nocardiaceae & & 82 & Uncultured archaea \\
81 & Cytophagaceae & & 82 & Uncultured archaea \\
95 & Clostridiaceae & & 93 & Crenarchaeota \\
160 & Acetobacteriaceae & & 142 & Crenarchaeota \\
185 & Chloroflexi & & 147 & Uncultured archaea \\
214 & Micrococcaceae & & 159 & Uncultured archaea \\
274 & Verumicrobia & & 164 & Uncultured archaea \\
367 & Acidobacteria & & 170 & Euryarchaeota \\
420 & Sphingomonaceae & & 186 & Crenarchaeota \\
440 & Clostridiaceae & & 218 & Uncultured archaea \\
450 & Bacillus & & 278 & Uncultured archaea \\
468 & Bacillus & 431 & Uncultured archaea \\
& & 461 & Uncultured archaea \\
\hline
\end{tabular}

TRFs are presented as base pairs

bacterial species were belonged to Actinobacteria, Firmicutes, Proteobacteria, Bacteroidetes, Chloroflexi, Verrumicrobia, and Acidobacteria. Three 3 TRFs (TRF51, TRF 75, TRF214) represented actinobacteria. Five TRFs (TRF66, TRF95, TRF440, TRF450, and TRF468) represented Firmicutes. Two TRFs (TRF 160, TRF 420) represented phyla Proteobacteria. The TRF367 represented Acidobacteria while TRF185 represented Chloroflexi. Archaeal TRFs mostly represented the uncultured species. Out of the 17 TRFs, 11 were uncultured archaea. Those were TRF57, TRF61, TRF82, TRF147, TRF159, TRF164, TRF 218, TRF 278, TRF 431, TRF 461, and TRF497. The euryarchaeal species were represented by TRF 75 , TRF170, and TRF468. The crenarchaeota were represented by TRF93, TRF142, and TRF186.

\section{Diversity analysis}

Irrespective of sampling sites, the diversity of archaea was higher than the bacteria (Table 3). The Simpson (D) index of bacteria varied from 0.87 to 0.53 . Archaeal simpson index varied in the range of $0.855-0.897$ with lowest in Jabalpur and highest in Bhopal. Shannon index $(\mathrm{H})$ for bacteria was high in Bhopal and low in Jabalpur. Similarly, Shannon index for Archaea was in the range of 3.027-3.155.

\section{PCA and cluster analysis}

Interactive effect of factors was estimated by the AMMI model (Table 4). Total degree of freedom was 212 for archaea and 152 for bacteria. AMMI model confirmed that the coverage of species by TRFLP was sufficient (sum of squares 1068.60 for bacteria and 959.69 for archaea). Interaction among TRFs and environment (locations) was further assessed by principal component analysis (PCA) with biplot (Fig. 3). PCA of the data matrix resulted in most of the data variance being explained by the first two principal components. For bacteria, PC1 explained $46.83 \%$ variation, and $31.07 \%$ of variation was rendered by $\mathrm{PC} 2$. Bhopal and Noida had similar microbial diversity pattern. TRF51 and TRF420 were dominant in Bhopal and Noida. PCA biplot of archaea indicated that Bhopal and Jabalpur had similar type of community (Fig. 4). TRF93 and TR468 were common in both sites. For archaea, PC1 explained $90.94 \%$ of variation and $9.05 \%$ of variation by PC2. Bray Curtis similarity grouped TRFs into separate clusters based on the pattern of fluorescence intensity (Fig. 5). Bacterial TRFs formed three clusters. TRF160 and TRF185 formed first cluster. Second cluster was constituted of TRF70, TRF66, TRF214, TRF95, TRF 81, and TRF75. Third cluster was constituted of TRF468, TRF440, TRF450, TRF420, TRF367, and TRF274. Archaea TRFs formed two major clusters. First cluster was constituted of TRF497, TRF278, TRF468, and TRF93 while, all other TRFs constituted second cluster.

\section{Discussion}

Bacterial species prevalent in rhizosphere of $J$. curcas were mainly belonged to Actinobacteria, Verrumicrobia, and Firmicutes. Actinobacteria has been found in rhizosphere of many plants, including cereal crops such as wheat (Zhao

Table 3 Diversity indices of bacteria and archaea in rhizosphere of Jatropha curcas sampled from different locations

\begin{tabular}{|c|c|c|c|c|c|c|}
\hline \multirow[t]{2}{*}{ Location } & \multicolumn{2}{|l|}{ Simpson (D) } & \multicolumn{2}{|l|}{ Shannon $(\mathrm{H})$} & \multicolumn{2}{|c|}{ Evennesss (H/S) } \\
\hline & Bacteria & Archaea & Bacteria & Archaea & Bacteria & Archaea \\
\hline Bhopal & $0.880 \pm 0.04$ & $0.897 \pm 0.025$ & $3.139 \pm 0.68$ & $3.111 \pm 0.23$ & $0.360 \pm 0.61$ & $0.311 \pm 0.024$ \\
\hline Jabalpur & $0.530 \pm 0.05$ & $0.855 \pm 0.017$ & $1.462 \pm 0.29$ & $3.027 \pm 0.25$ & $0.139 \pm 0.25$ & $0.226 \pm 0.033$ \\
\hline Noida & $0.875 \pm 0.08$ & $0.873 \pm 0.021$ & $3.071 \pm 0.074$ & $3.155 \pm 0.35$ & $0.326 \pm 0.47$ & $0.286 \pm 0.057$ \\
\hline
\end{tabular}


Table 4 Interaction of factors (TRFs and locations) on microbial diversity

\begin{tabular}{|c|c|c|c|c|c|c|}
\hline \multirow[t]{2}{*}{ Source } & \multicolumn{3}{|c|}{ Archaea } & \multicolumn{3}{|c|}{ Bacteria } \\
\hline & $d f$ & SS & MS & $d f$ & SS & MS \\
\hline Total & 212 & 3737.90336 & 17.63162 & 152 & 2312.64973 & 15.21480 \\
\hline TRFs & 70 & 2448.90457 & 34.98435 & 50 & 1341.92820 & 26.83856 \\
\hline ENVs (location) & 2 & 0.00001 & 0.00001 & 2 & 0.00002 & 0.00001 \\
\hline $\mathrm{T} \times \mathrm{E}$ & 140 & 1288.99878 & 9.20713 & 100 & 970.72151 & 9.70722 \\
\hline IPCA 1 & 71 & 1068.60875 & 15.05083 & 51 & 959.69960 & 18.81764 \\
\hline IPCA 2 & 69 & 220.39003 & 3.19406 & 49 & 11.02190 & 0.22494 \\
\hline
\end{tabular}

ANOVA for AMMI model for both archaeal and bacterial TRFs. Model used to determine interactive effect of the factors like TRFs abundance, number and environment

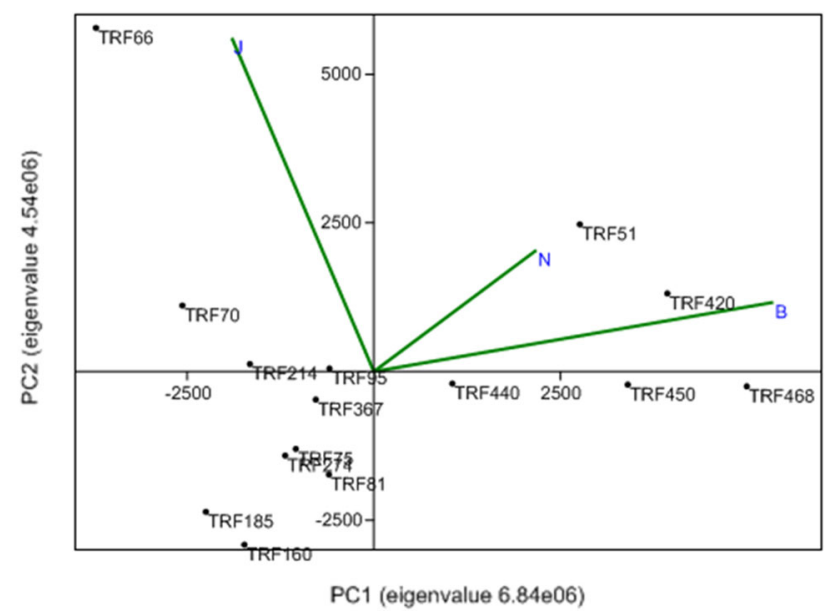

Fig. 3 Principal component analysis (PCA) of bacterial TRFs. PCA represent vectors of variables (locations: $B$-Bhopal, $J$-Jabalpur, $N$ Noida) and factors of TRFs or ribotypes retrieved from the rhizosphere of Jatropha curcas. Eigenvalue scaled principal components (PC) 1 represent $46.83 \%$ of variation and PC2 represent $31.07 \%$ variation. In PCA, arrows with narrow angles are strongly correlated; arrows that are perpendicular show no correlation and arrows in opposite directions indicate negative correlation. More confidence characterizes comparisons between variables with longer arrows, as inferences made from variables located near the center of the diagram are often imprecise

et al. 2012; Mingma et al. 2014). Streptomyces are major species of Actinobacteria, that are commonly found in roots of crops and terrestrial plants (Liu et al. 2015). Actinomycetes has been isolated from the root of the oilseed plant (Xing et al. 2012). Nocardioides panzhihuaensis has been reported from the roots of $J$. curcas (Qin et al. 2012). However, information regarding the prevalence of Firmicutes or Clostridia in the rhizosphere of J. curcas is limited. TRF fragments representing Verrumicrobia, and Chloroflexi were retrieved from the rhizosphere of J. curcas. In a study, microbial diversity of a native waste-land and planted with $J$. curcas was evaluated. There was a striking increase in the members of Proteobacteria as well

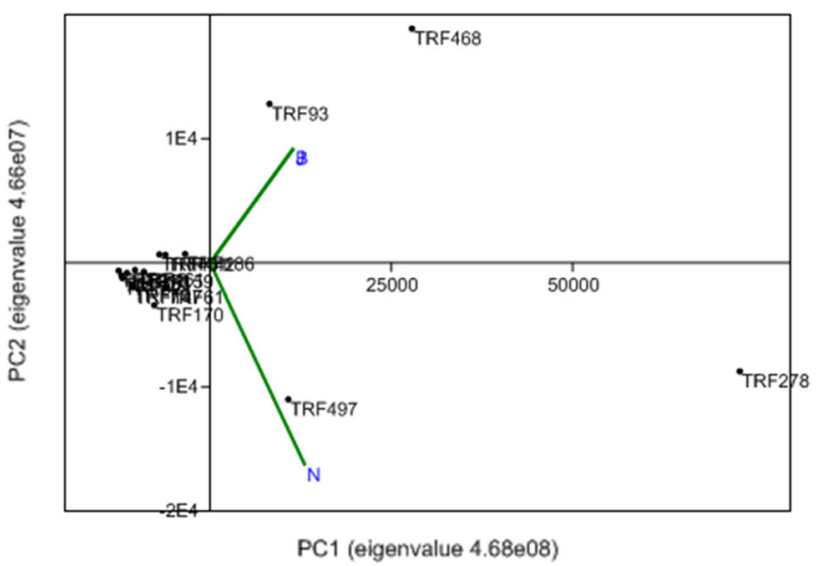

Fig. 4 Principal component analysis (PCA) biplot (PC1 and 2) of archaeal TRFs. PCA represent vectors of variables (locations: $B$ Bhopal, J-Jabalpur, $N$-Noida) and factors of TRFs or ribotypes retrieved from the rhizosphere of the Jatropha curcas. Eigenvalue scaled principal components (PC) 1 represent $90.94 \%$ of variation and PC2 represent $9.05 \%$ variation. In PCA, arrows with narrow angles are strongly correlated; arrows that are perpendicular show no correlation and arrows in opposite directions indicate negative correlation. More confidence characterizes comparisons between variables with longer arrows, as inferences made from variables located near the center of the diagram are often imprecise

as of Bacteroidetes in Jatropha planted soil than the native soil. In contrast, there was a decline in the Acidobacteria and Chloroflexi community in the fields planted with $J$. curcas.

T-RFLP also indicated the presence of Bifidobacteria $s p$, Sphingomonas, Bacillus subtillis, Clostridium, and Exiguobacterium in rhizosphere of J. curcas. The least abundant species were Dehalogenomonas, Acidobacteria, Acetobacteria, Verrumicrobia. Bifidobacteria comes under Acenitobacter and exhibits PGPR activities. Acinetobacter are plant growth promoters (Huddedar et al. 2002) and they produce phyto hormones (Fiester and Actis 2013), solubilize phosphate (Rokhbakhsh-Zamin et al. 2011), and also produce siderophores (Higgins et al. 2012). Acinetobacter suppresses phytopathogenic fungi, such as Cryphonectria 
Fig. 5 Brays-curtis similarity clustering of bacterial (left) and archaeal (right) TRFs

(ribotypes) retrieved from the rhizosphere of Jatropha curcas. The MDS plot gives a 2D representation of relative similarities. TRFs with similar extent of occurrence among the samples are relatively closely spaced

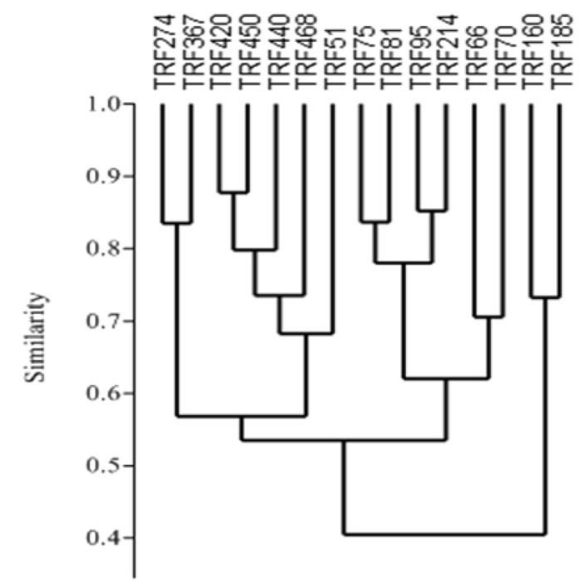

parasitica, Phytophthora capsici, and Rhizoctonia solani (Maindad et al. 2014). TRFs representative of Sphingomonas were also found in the rhizospheric samples. These organisms has been found in the rhizosphere of rice (Shahi et al. 2013), apple (Caputo et al. 2015), and ginseng (Singh et al. 2015). Sphingomonas promotes plant growth by producing growth hormones, gibberllins and indole acetic acid (Myresiotis et al. 2012). Bacillus subtilis, belongs to the phylum Firmicutes, has been found in a wide variety of environments and plants. Bacillus $s p$ produces phytohormones and exhibits ACC deaminase activity (Bharti et al. 2013). Exiguobacteria are gram positive, rod shaped, yellow pigmented bacterium has been found in rhizospheric soil of apple. These bacteria produce siderophore for better nutrient uptake. These strains also produce hydrogen cyanide ( $\mathrm{HCN}$ ) and volatile compounds to protect plants from pathogens like Rhizoctonia solani, Sclerotium rolfsii, Pythium and Fusarium oxysporum (Selvakumar et al. 2009).

There were 17 archaeal TRFs found in the rhizosphere of $J$. curcas and out of which 11 were affiliated to uncultured archaea. Three TRFs were affiliated to Crenarchaea and other three TRFs were affiliated to Euryarchaea. Archaea has been found in the rhizosphere of different terrestrial plants but mostly were observed in aquatic plants. In temperate grassland pasture, the archaeal communities are mainly Crenarchaeota (Nicol et al. 2003). In flooded rice soil ecosystem the ammonia oxidizing archaea are abundant in the rhizosphere than in the bulk soil. The rice cultivation stimulates the abundance of both the nitrifying ammonia oxidizing archaea than ammonia oxidizing bacteria (Chen et al. 2008). A study on the microbial community of three boreal forest tree species (Scots pine, silver birch, and Norway spruce), archael species like methanogenic euryarchaeota belonging to Methanolobus sp. and Methanosaeta sp. were detected on the roots. In this study the most commonly archaeal 16S rRNA gene sequences were Crenarchaeota of $1.1 \mathrm{~b}$ and 1.1c (Bomberg et al. 2011). Other TRFs represented uncultured archaea like, TRF93 (Crenarchaea), TRF278 (archaea of environmental samples), TRF 468 (Euryarchaea), TRF497 (archaea of environmental samples). Relative abundance of these TRFs followed the trend of TRF $278>$ TRF468 $>$ TRF93 $>$ TRF497 $\quad$ (Fig. 2). Crenarchaeota probably were involved in $\mathrm{N}$ transformation (nitrification) in rhizosphere of $J$. curcas. However, further research need to be undertaken to verify the role of these archaea on $\mathrm{N}$ transformation.

The microbial diversity was evaluated through the Simpson, Shannon and evenness indices (Haegeman et al. 2013). Simpson's Index (D) measures the probability that two individuals randomly selected from a sample will belong to the same species. Index, 0 represents infinite diversity and 1, no diversity. Bhopal and Noida had high bacterial diversity than Jabalpur. Similar values has been observed in rhizosphere of maize (Pathan et al. 2015). The Shannon index $(\mathrm{H})$ is commonly used to characterize species diversity. It accounts for both abundance and evenness of the species. Similar results have been observed in the Brazilian Atlantic forest soil which is one of the 25 biodiversity hot spots in the world. In these sites the Shannon diversity indices was in the range of 4.12-3.57, ascribed to high microbial diversity (Faoro et al. 2010). Evenness measures relative abundance of the different species. Diversity was high in Bhopal and Noida than Jabalpur. Probably, soil $\mathrm{N}$ was related to diversity values. In a study, it was shown that soil with limited inorganic $\mathrm{N}$ adversely affected microbial diversity (Thébault et al. 2014). PCA biplot revealed that both Bhopal and Noida possessed similar microbial population. Organic $\mathrm{C}$ and total $\mathrm{N}$ was high in these soils than Jabalpur. Microbial diversity corresponded with the organic carbon and nitrogen content of soils. Environmental factors that influence microbial community composition and diversity include pH (Eichorst et al. 2007), organic C (Zhou et al. 2002), and available N (Fierer et al. 2003). The expression of 
microbial activities strongly depends on the organic $\mathrm{C}$ and available N content of soil. Soil organic carbon is heterogeneously distributed among different-sized primary particles, forming organo-mineral complexes that respond differently to the plant and environmental factors (Christensen et al. 2001). Microbial diversity of soils varied relatively with the cation exchange capacity (CEC). The capacity of the soil to capture the cations (for example $\mathrm{Ca}^{2+}, \mathrm{Mg}^{2+}, \mathrm{K}^{+}, \mathrm{Na}^{+}, \mathrm{Al}^{3+}, \mathrm{Fe}^{2+}$, etc.) is called CEC. These cations are held together by the negatively charged clay and organic matter particles in the soil. These cations are easily exchanged with other soil cations and help in microbial metabolism. Probably, CEC favored microbial activity and increased the microbial diversity (Taylor et al. 2002). Clay content of soil reflects organic carbon, CEC and nitrogen (Xue et al. 2013). Therefore, soils with high clay content had high microbial diversity.

Ribotypes like TRF 420 (Sphingomonas sp) and TRF51 (Bifidobacteria) were dominant in Bhopal and Noida. Whereas, the TRF66 (Streptococcus) and TRF70 (Acinetobacter) were dominant in Jabalpur. Actinomycetes and Acinetobacter are prevalent in low nutrient soils. Acinetobacter grows well under low nutrient situation and many species form intracellular inclusions of nutrients in the form of polyhydroxy-alkanoates (Abbott et al. 1974). PCA biplot of archaeal TRFs indicated that Bhopal and Jabalpur were closely placed. TRF93 and TRF468 were abundant in Bhopal and Jabalpur samples, while TRF 497, TRF 278 were dominant in the samples collected from Noida. Further studies are essential to explain the linkage between soil properties and archaeal diversity.

Brays curtis algorithm clustered the TRFs into different groups. The clustering depends on fluorescence intensity of the TRFs. If their fluorescence intensity of TRFs varies similarly they are clustered together. For example, TRF 66-TRF 70 and TRF 274-TRF 367 were closely placed. In case of archaea TRF 93, TRF 468, TRF 278, TRF 497 formed one cluster because these TRFs were most dominant. TRF 61, TRF 142, TRF 186, TRF 431 clustered together due to medium range of fluorescence intensity. TRF 57, TRF 82, TRF 164, TRF 218 formed another cluster due to low fluorescence intensity. This clustering strategies has been used to differentiate TRFs of methanotrophs in rice and forest soil (Mohanty et al. 2007). Similar approach has been used to cluster bacterial bph gene in Amazon dark soil to understand microbial diversity (de Lima Brossi et al. 2014). Archaea specific TRF 93, TRF 278, TRF468, TRF 497 were clustered together due to high abundance than other TRFs. Additive main effects and multiplicative interaction model (AMMI) inferred that TRFs were the significant factors than sampling sites. Similar results has been reported in a study determining the microbial diversity in soil during decomposition of $\mathrm{Bt}$ rice straw (Lu et al. 2010) and endophytes of potato (Pageni et al. 2013). Here, we show that the structure of bacterial and archaeal communities is not random at the spatial scale because the diversity and composition of bacterial and archaeal community in rhizosphere of $J$. curcas was largely similar. These results suggest that, to some degree, the large scale biogeographical patterns of rhizospheric microorganisms are fundamentally similar for same plant taxa.

To compare bacterial and archaeal diversity and community structure across soils, T-RFLP method was used. This method quantifies sequence variability in the $16 \mathrm{~S}$ rRNA gene extracted from soil, producing a DNA fingerprint for each microbial community as unique ribotypes (restriction fragments). Although other approaches like sequence analysis of $16 \mathrm{~S}$ rRNA clone libraries and pyrosequencing provides more detailed phylogenetic information, the T-RFLP method is better suited for analyzing a large number of samples (Burke et al. 2008). It is also commonly used for determining diversity and composition of highly complex microbial communities (Osborne 2014). Major limitation of the T-RFLP method is that it underestimates total bacterial diversity because the method resolves only a limited number of bands per gel (generally $<100$ ), and bacterial species can share restriction fragments (Dunbar et al. 2001). However, T-RFLP estimates of microbial community structure have been found to be generally robust and concur with alternative approaches such as 454 pyrosequencing in documenting microbial community differences (Pilloni et al. 2012).

\section{Conclusion}

This study exhibited bacterial and archaeal diversity in rhizosphere of J. curcas. Dominant bacterial species were Actinobacteria, Firmicutes, Acidobacteria, Verrumicrobiaceae, and Chlroflexi. In case of archaea, the dominant species were uncultured Archaea, Crenarchaea and Euarchaea. Bacterial species detected in the rhizosphere of $J$. curcas were mostly plant growth promoters. Microbial diversity was related to soil $\mathrm{C}$ and $\mathrm{N}$ content and could be important drivers of the microbial community composition. Although the PGPR activities of the bacterial groups inhabiting the rhizosphere of $J$. curcas are known but literature on archaea is scarce. Further research is warranted to reveal significance of archaea on the growth of $J$. curcas.

Acknowledgements This work is part of the project entitled "Metagenomic characterization and spatio-temporal changes in the prevalence of microbes involved in nutrient cycling in the rhizoplane of bioenergy crop Jatropha curcas", funded by Dept of Biotechnology, Govt of India. 


\section{Compliance with ethical standards}

Conflict of interest Authors declare no conflict of interest of any type.

Open Access This article is distributed under the terms of the Creative Commons Attribution 4.0 International License (http:// creativecommons.org/licenses/by/4.0/), which permits unrestricted use, distribution, and reproduction in any medium, provided you give appropriate credit to the original author(s) and the source, provide a link to the Creative Commons license, and indicate if changes were made.

\section{References}

Abbott BJ, Laskin AI, McCoy CJ (1974) Effect of growth rate and nutrient limitation on the composition and biomass yield of Acinetobacter calcoaceticus. Appl Microbiol 28:58-63

Bharti N, Yadav D, Barnawal D et al (2013) Exiguobacterium oxidotolerans, a halotolerant plant growth promoting rhizobacteria, improves yield and content of secondary metabolites in Bacopa monnieri (L.) Pennell under primary and secondary salt stress. World J Microbiol Biotechnol 29:379-387

Bomberg M, Münster U, Pumpanen J et al (2011) Archaeal communities in boreal forest tree rhizospheres respond to changing soil temperatures. Microb Ecol 62:205-217

Burke DJ, Dunham SM, Kretzer AM (2008) Molecular analysis of bacterial communities associated with the roots of Douglas fir (Pseudotsuga menziesii) colonized by different ectomycorrhizal fungi. FEMS Microbiol Ecol 65:299-309

Caputo F, Nicoletti F, Picione FDL, Manici LM (2015) Rhizospheric changes of fungal and bacterial communities in relation to soil health of multi-generation apple orchards. Biol Control 88:8-17

Chen XP, Zhu YG, Xia Y et al (2008) Ammonia-oxidizing archaea: important players in paddy rhizosphere soil? Env Microbiol 10:1978-1987

Christensen S, Degorska A, Prieme A (2001) Methane oxidation in Polish forest soils of contrasting atmospheric pollution. Atmos Environ 35:2795-2798. doi:10.1016/S1352-2310(00)00207-7

Culman SW, Gauch HG, Blackwood CB, Thies JE (2008) Analysis of T-RFLP data using analysis of variance and ordination methods: a comparative study. J Microbiol Methods 75:55-63

de Lima Brossi MJ, Mendes LW, Germano MG et al (2014) Assessment of bacterial bph gene in Amazonian Dark Earth and their adjacent soils. PLoS One 9(6):e99597

De Mendiburu F (2014) Agricolae: statistical procedures for agricultural research. R Package Version 1:1-6

Dunbar J, Ticknor LO, Kuske CR (2001) Phylogenetic specificity and reproducibility and new method for analysis of terminal restriction fragment profiles of 16S rRNA genes from bacterial communities. Appl Environ Microbiol 67:190-197

Eichorst SA, Breznak JA, Schmidt TM (2007) Isolation and characterization of soil bacteria that define Terriglobus gen. nov., in the phylum Acidobacteria. Appl Environ Microbiol 73:2708-2717

Faoro H, Alves AC, Souza EM et al (2010) Influence of soil characteristics on the diversity of bacteria in the Southern Brazilian Atlantic Forest. Appl Environ Microbiol 76:4744-4749

Fierer N, Allen AS, Schimel JP, Holden PA (2003) Controls on microbial $\mathrm{CO} 2$ production: a comparison of surface and subsurface soil horizons. Glob Change Biol 9:1322-1332

Fiester SE, Actis LA (2013) Stress responses in the opportunistic pathogen Acinetobacter baumannii. Future Microbiol 8:353-365
Haegeman B, Hamelin J, Moriarty J et al (2013) Robust estimation of microbial diversity in theory and in practice. ISME $\mathrm{J}$ 7:1092-1101

Higgins PG, Stefanik D, Page MG et al (2012) In vitro activity of the siderophore monosulfactam BAL30072 against meropenem-nonsusceptible Acinetobacter baumannii. J Antimicrob Chemother 67:1167-1169

Huddedar SB, Shete AM, Tilekar JN et al (2002) Isolation, characterization, and plasmid pUPI126-mediated indole-3-acetic acid production in Acinetobacter strains from rhizosphere of wheat. Appl Biochem Biotechnol 102:21-39

Islam AA, Yaakob Z, Ghani JA, Anuar N (2014) Jatropha curcas L.: A future energy crop with enormous potential. In: Biomass and bioenergy. Springer, pp 31-61

Johnson RA, Wichern DW (2002) Applied multivariate statistical analysis, vol 5, no 8. Prentice Hall, Upper Saddle River, NJ

Liu C, Guan X, Jin P, et al (2015) Dactylosporangium cerinum sp. nov., a novel actinobacterium isolated from the rhizosphere of Pinus koraiensis Sieb. et Zucc. Antonie Van Leeuwenhoek, pp 1-9

$\mathrm{Lu} \mathrm{H}, \mathrm{Wu} \mathrm{W}$, Chen Y et al (2010) Decomposition of Bt transgenic rice residues and response of soil microbial community in rapeseed-rice cropping system. Plant Soil 336:279-290

Maindad DV, Kasture VM, Chaudhari H et al (2014) Characterization and fungal inhibition activity of siderophore from wheat rhizosphere associated Acinetobacter calcoaceticus strain HIRFA32. Indian J Microbiol 54:315-322

Mingma R, Pathom-aree W, Trakulnaleamsai S et al (2014) Isolation of rhizospheric and roots endophytic actinomycetes from Leguminosae plant and their activities to inhibit soybean pathogen, Xanthomonas campestris pv. glycine. World J Microbiol Biotechnol 30:271-280

Mohanty SR, Bodelier PLE, Conrad R (2007) Effect of temperature on composition of the methanotrophic community in rice field and forest soil. FEMS Microbiol Ecol 62:24-31

Mohanty SR, Kollah B, Banerjee K et al (2012) Methane consumption and dynamics of microbial population in the rhizosphere of bioenergy crop Jatropha curcas in tropical Indian Soil. Proc Biofest, pp 12-13

Mohanty S, Kollah B, Chaudhary RS et al (2015) Methane uptake in tropical soybean-wheat agroecosystem under different fertilizer regimes. Environ Earth Sci 74:5049-5061

Myresiotis CK, Vryzas Z, Papadopoulou-Mourkidou E (2012) Biodegradation of soil-applied pesticides by selected strains of plant growth-promoting rhizobacteria (PGPR) and their effects on bacterial growth. Biodegradation 23:297-310

Nicol GW, Glover LA, Prosser JI (2003) The impact of grassland management on archaeal community structure in upland pasture rhizosphere soil. Env Microbiol 5:152-162

Oksanen J, Kindt R, Legendre P et al (2007) The vegan package. Community ecology package, $R$ package version 1 , pp 9-25

Osborne CA (2014) Terminal Restriction Fragment Length Polymorphism (T-RFLP) Profiling of Bacterial 16S rRNA Genes. In: Environmental Microbiology. Springer, pp 57-69

Pageni BB, Lupwayi NZ, Larney FJ et al (2013) Populations, diversity and identities of bacterial endophytes in potato (Solanum tuberosum L.) cropping systems. Can J Plant Sci 93:1125-1142

Pathan SI, Ceccherini MT, Hansen MA et al (2015) Maize lines with different nitrogen use efficiency select bacterial communities with different $\beta$-glucosidase-encoding genes and glucosidase activity in the rhizosphere. Biol Fertil Soils 51:995-1004

Pérez Y, Schenck NC (1990) A unique code for each species of VA mycorrhizal fungi. Mycologia 82:256-260

Pilloni G, Granitsiotis MS, Engel M, Lueders T (2012) Testing the limits of 454 pyrotag sequencing: reproducibility, quantitative

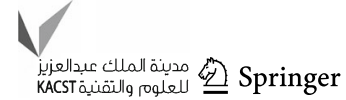


assessment and comparison to T-RFLP fingerprinting of aquifer microbes. PLoS One 7:e40467

Qin S, Yuan B, Zhang Y-J et al (2012) Nocardioides panzhihuaensis sp. nov., a novel endophytic actinomycete isolated from medicinal plant Jatropha curcas L. Antonie Van Leeuwenhoek 102:353-360

Rokhbakhsh-Zamin F, Sachdev D, Kazemi-Pour N et al (2011) Characterization of plant-growth-promoting traits of Acinetobacter species isolated from rhizosphere of Pennisetum glaucum. J Microbiol Biotechnol 21:556-566

Rösch C, Bothe H (2005) Improved assessment of denitrifying, N2fixing, and total-community bacteria by terminal restriction fragment length polymorphism analysis using multiple restriction enzymes. Appl Environ Microbiol 71:2026-2035

Selvakumar G, Joshi P, Nazim S et al (2009) Exiguobacterium acetylicum strain 1P (MTCC 8707) a novel bacterial antagonist from the North Western Indian Himalayas. World J Microbiol Biotechnol 25:131-137

Shahi SK, Rai AK, Tyagi MB et al (2013) Rhizosphere of rice plants harbor bacteria with multiple plant growth promoting features. Afr J Biotechnol 10:8296-8305

Shyu C, Soule T, Bent SJ et al (2007) MiCA: a web-based tool for the analysis of microbial communities based on terminal-restriction fragment length polymorphisms of $16 \mathrm{~S}$ and $18 \mathrm{~S}$ rRNA genes. Microb Ecol 53:562-570

Singh P, Kim Y-J, Hoang V-A et al (2015) Sphingomonas panacis sp. nov., isolated from rhizosphere of rusty ginseng. Antonie Van Leeuwenhoek 108:711-720
Taylor JP, Wilson B, Mills MS, Burns RG (2002) Comparison of microbial numbers and enzymatic activities in surface soils and subsoils using various techniques. Soil Biol Biochem 34:387-401

Thébault A, Clément J-C, Ibanez S et al (2014) Nitrogen limitation and microbial diversity at the treeline. Oikos 123:729-740

Tipayno S, Kim CG, Sa T (2012) T-RFLP analysis of structural changes in soil bacterial communities in response to metal and metalloid contamination and initial phytoremediation. Appl Soil Ecol 61:137-146

Xing K, Bian GK, Qin S et al (2012) Kibdelosporangium phytohabitans sp. nov., a novel endophytic actinomycete isolated from oil-seed plant Jatropha curcas L. containing 1-aminocyclopropane-1-carboxylic acid deaminase. Antonie Van Leeuwenhoek 101:433-441

Xue K, Wu L, Deng Y et al (2013) Functional gene differences in soil microbial communities from conventional, low-input, and organic farmlands. Appl Environ Microbiol 79:1284-1292

Yi H, Kim H-J, Kim C-G et al (2009) Using T-RFLP to assess the impact on soil microbial communities by transgenic lines of watermelon rootstock resistant to cucumber green mottle mosaic virus (CGMMV). J Plant Biol 52:577-584

Zhao K, Penttinen P, Chen Q et al (2012) The rhizospheres of traditional medicinal plants in Panxi, China, host a diverse selection of actinobacteria with antimicrobial properties. Appl Microbiol Biotechnol 94:1321-1335

Zhou J, Xia B, Treves DS et al (2002) Spatial and resource factors influencing high microbial diversity in soil. Appl Environ Microbiol 68:326-334 